\title{
Adaptive learning and reduced cognitive uncertainty in a financial organization
}

Yngve Antonsen, Odd-Arne Thunberg and Tom Tiller

University of Troms $\varnothing$, Troms $\varnothing$, Norway

\begin{abstract}
Purpose - This paper analyses and discusses the "learning activities" that comprise obligatory learning at work by employees each month. The management strategy is to use these learning activities to spread knowledge, exchange experience and implement new skills within the organisation. The purpose of this paper is to answer the question: to what extent do these learning activities at the Bank promote adaptive or developmental learning? In addition, the paper asks whether the learning activities amplify or reduce the employees' cognitive uncertainty in resolving work-related issues.
\end{abstract}

Design/methodology/approach - This case study is part of a four-year project about workplace learning, in a bank with more than 700 employees located in more than 50 departments of various sizes in Norway.

Findings - The research shows that time regularly set aside for necessary information updates and workplace learning is important in a hectic work situation with a strong focus on sales. Within the organization studied, learning is strongly focused on factual knowledge, routines and rehearsal.

Research limitations/implications - Although this qualitative study is based on multiple and triangulated observations the methodology is limited in that it raises the question of how far one can accept the validity of generalizations arising from one case only.

Originality/value - This research adds to the literature on adaptive learning and reduced cognitive uncertainty and will be of interest to those wishing to simplify work-related issues. Keywords Learning processes, Learning styles, Cognition, Financial institutions, Norway

\section{Paper type Research paper}




\section{Introduction}

Traditionally, different learning initiatives have been designed to reduce cognitive uncertainty about how working tasks should be carried out (Michel 2007). Organisations seek to simplify work-related issues, in order to maintain continuity and solve problems, by instructing employees to read, rehearse and practice various formulas and routines (March 1991). The breakdown in parts of the banking world in November 2008 led to increased levels of cognitive uncertainty (Krugman 2009). Cognitive uncertainty is connected to low initial confidence in using one's personal skills in handling a new situation. This study investigates learning at work and cognitive uncertainty in a financial organization. Learning at work has established itself as one of the core developmental concepts in the modern world of banking and finance (Barnett 1999; Illeris 2004). Empirical research is needed to establish what kind of learning employees are expected to execute at work and how this amplifies or reduces cognitive uncertainty in organisations.

This case study is part of a four year project about workplace learning, in a bank with more than 700 employees located in more than 50 departments of various sizes in Norway. The Bank is highly driven both in business and personal banking, with very good profits and a top international A Fitch Rating. We analyse and discuss the "learning activities" that comprise obligatory learning at work by employees each month. The management strategy is to use these learning activities to spread knowledge, exchange experience and implement new skills within the organisation. We pose the question: To what extent do these learning activities at the Bank promote adaptive or developmental learning? In addition, we ask whether the learning activities amplify or reduce the employees' cognitive uncertainty in resolving workrelated issues.

\section{Employees' learning at work}

The concept of workplace learning is complex and two levels have been defined:

- adaptive learning involves learning to acquire facts or perform work tasks and methods through prescribed routines by repetition. Knowledge is seen as a commodity 
delivered in 'sealed packages' without conscious influence on the part of the learner (Ellström 2001).

- developmental learning shifts the focus onto the ability of employees to influence evaluation of the work processes results and also define tasks and methods. Employees ask critical questions and review problems, objectives, routines, practices and ideas promotes developmental learning (Boud, Cressey \& Docherty 2006). They reflect on unclear situations and consider alternative action while actively analysing and planning of parts of the work process (Ellström 2001).

The following model elaborates aspects of adaptive and developmental learning, illustrating the greater scope for learner initiative offered by developmental learning:

Table 1: Adaptive and developmental learning

\begin{tabular}{|c|c|c|c|c|}
\hline \multirow{2}{*}{$\begin{array}{c}\text { Aspects of the } \\
\text { Work Learning } \\
\text { Situation }\end{array}$} & \multicolumn{2}{|c|}{ Adaptive Learning } & \multicolumn{2}{c|}{ Developmental Learning } \\
\cline { 2 - 5 } & Reproductive & Productive type 1 & Productive type 2 & Creative \\
\hline Task & Given & Given & Given & Not given \\
\hline Method & Given & Given & Not given & Not given \\
\hline Results & Given & Not given & Not given & Not given \\
\hline
\end{tabular}

(Ellström 2001)

Reproductive learning is the lowest level of learning (Marton \& Säljö 1976). The employee follows a formula for achieving an objective fixed in advance, motivated by rewards and punishment. This learning is based on trial, error and imitation. On the next level we find productive learning 1 where both the task and the method are given, while the employee evaluates the result. Such learning reduces the employees influence to improve the task based on reflection (Ellström 2001). Productive learning 2 additionally require that the learner selects the method for solving the work task. At the highest level we find creative learning where the learner uses her own authority and selects methods, evaluates the result and, significantly, defines the work task in order to diagnose the situation. Creative learning requires the learner to identify and define the demands of the situation. This also involves reflecting around unclear situations consider alternatives and different actions. Employees are actively involved in a process of learning that focuses on the analyses and planning of parts of the work process (Ellström 2001). The two lower levels of learning require passive adoption by the employee, while the higher two encourage active development of the employee. If routinised adaptive learning becomes dominant, this can result in non-negotiable solutions to 
work-related issues, weaken constructive reflection and thereby limit valuable opportunities for renewal within the organisation.

Theorists argue that key factors in enhancing employees' learning at work are time for interaction, reflection, scope for creativity and a high degree of active participation (Boud, Cressey \& Docherty 2006; Dewey 1991). A review of research into workplace learning reveals that the ability of managers to implement these factors has received little attention (Fenwick 2008). Managers have the authority to define and make demands to which others must choose whether or not to conform (Emerson 1962). Compulsory workplace learning can be used as a management tool to increase the degree of control over employees as they engage in work tasks (Ellström 2001). The criticism of 'recipe learning' is based on an excessive emphasis on lectures, demonstrations and one-way communication in which learners are not active participants in their own learning (Dewey 1991). The ability of individuals to influence their own learning processes fosters greater commitment (O'Reilly \& Chatman 1996). A strategy for increasing developmental learning at the workplace includes both psychological and social 'elbow room' for employees to influence decisions (Bottrup \& Clematide 2005). Theories of workplace learning in general therefore emphasises the importance of employees being able to direct their own learning, coupled to actual problems that arise from their daily work experiences (Barnett 1999). Reflection is increasingly seen as central in creating learning and change in working life (Schøn 1987). Reflection involves a conscious assessment of the connection between actions and their consequences (Argyris \& Schön 1996). Critical reflection also involves assessing why a specific course of action is preferable. It assures quality in learning by critically assessing opinions, theories and practice from various positions and perspectives (Dewey 1991).

Participatory critical reflection between employees is an important means of ensuring personal engagement, forming opinions and promoting change (Boud, Cressey \& Docherty 2006; Wenger 2000). A strategy by which employees critically reflect together might also lead to new actions that increase productivity (Boud, Cressey \& Docherty 2006) The goal of such reflective work is to overcome the problem of lack of time and to counter demands for fast and unreflective decisions (Senge 1999). Consultative and open-minded management is important for initiating collaborative reflection (Boud, Cressey \& Docherty 2006) and it will critically question working practices at three levels: the individual employee, the department and the whole organisation (Senge 1999). Such critical reflection are dependent on a capacity 
for organisational learning which involves changing of routines or practices independent of individual actors (Scott 1992). Argyris and Schön (1996) make an important distinction between adaptive changes as opposed to simple adjustments of routines without thorough analysis (single loop learning) and developmental learning which they term double loop learning which involves total adjustments based on assessment of strategies and values.

Increasingly in professional working life employees are required to document their formal training and educational qualifications. This is seen as quality assurance that they are ready to perform the tasks required in their work. An empirical inquiry points out how new demands for skills increase the need for workers to keep their skills up-to-date, both through the internet and by reading the literature (Goldman et al. 2009). The acquisition of new technical knowledge parallels work functions in other occupations such as dealing with customers or patients (Goldman et al. 2009). Continuous adjustments, standardisation and the introduction of new reforms, regulations, strategies and research demand keeping up-to-date at a pace proportionate to the changes. Where error in performance cannot be tolerated, training by means of repeating routines and processes is a mechanism for protecting work functions (Goldman et al. 2009). Rehearsal and practice ensure that work skills, patterns and solutions are drilled to the highest degree of perfection. Such technical learning of work tasks contains little room for manoeuvre (Dreyfus \& Dreyfus 1986). Focus on practising routines and drills, requires employees to change their patterns of behaviour and become secure in solving workrelated tasks (Levinthal \& March 1993). A negative consequence may be that their activity is then reduced to following a formula; their ability to think creatively disappears and blind obedience to managerial control is increased (Argyris \& Schön 1996; Jørgensen \& Warring 2002). There is a marked gulf between so-called non-reflective 'recipe learning' and an active, reflective 'learn-to-think-for-yourself' learning (Dewey 1991). Thus, the issue of adaptive and developmental learning is complementary with theories of reduced or amplified cognitive uncertainty.

\section{Reduced or amplified cognitive uncertainty}

Distributed cognitive theory emphasises the significance of individuals learning in varied environments, context and through inter-personal interaction. Cognition is not just distributed 
within the heads of individuals. Because cognition changes through use of artefacts and interpersonal interactions (Michel 2007). As a result will organisational strategies emphasising either adaptive or developmental learning differently influence individuals' cognitive uncertainty in how to resolve work tasks. Cognitive uncertainty can be defined as "a subjectively-perceived state of 'low prior confidence' concerning the accuracy or relevance of one's knowledge about a new situation" (Trope \& Liberman 1996). In particular, new employees are vulnerable to cognitive uncertainty when faced with new tasks. Their uncertainty is based on a lack of the skills to handle every-day tasks due to unclear, inadequate or contradictory information. Cognitive uncertainty makes it difficult to distinguish between information that is relevant and irrelevant. This lack of clarity complicates the choices between alternative solutions or removes the possibility of finding solutions (Michel 2007).

Cognitive uncertainty is an important dimension in any analysis of learning within work practices. When people look for set routines it is because these contribute to predictability (Senge 1999). If it is the intention of the senior management to reduce cognitive uncertainty amongst their employees, it is reasonable to believe that one would confirm or strengthen an already-established adaptive learning tradition. Training reduces cognitive uncertainty in workplaces and has traditionally been made a priority because it contributes to a more routine-based working environment for staff. It is assumed that cognitive uncertainty can be reduced through tightening up guidelines and standardising procedures (Michel 2007) in which there is no need for questions and reflection. Within workplaces or operations that do not tolerate large margins of operational error, reduction of cognitive uncertainty by standardising procedures is an absolute necessity. Organisations and employees are thus assured that tasks will be carried out in the simplest and most effective manner. In this case, employees themselves must learn the procedures to be implemented. Research indicates that employees see routines and procedures as absolutely necessary to reduce uncertainty when work tasks are experienced as hectic and stressful (Goldman et al. 2009).

The challenge is that when employees take pre-determined decisions in uncertain, complex areas that are not necessarily susceptible to clear-cut solutions, this can hinder reflection (Giddens 1990). Conversely, deliberately amplified cognitive uncertainty amongst employees will stimulate critical questions about work tasks and lead to more independent reflection from employees (Michel 2007). Innovative businesses such as Google, Xerox and Apple 
computer have been successful in creating conditions for collaborative developmental learning in which cognitive uncertainty is amplified (Michel 2007). A large international investment bank had a strategy in which employees were given the responsibility and trusted to ask, discuss and reflect their way to decisions based on careful analysis of uncertainty (Michel, A \& Wortham 2009). Such collaborative organisations may have a comparative advantage in that they will be less vulnerable in the absence of key personnel. Collaborative organisations are more focused on how the organisation as an entity can resolve work issues. Organisations that have a strong collective focus not only increase individual learning, but also promote corporate learning and reflection (Wenger 2000).

How employees tackle the uncertainty of rapid change is also regarded as important for the survival of the organisation. Decisions that have to be based on uncertainty require a way of thinking that can no longer be based purely on technical-economic rationality (Beck 1997; Giddens 1990). Uncertainty can therefore not simply be banished or reduced to insignificance but should be taken seriously in organisations in general (Beck 1997; Giddens 1990) and financial institutions in particular (Krugman 2009). Focusing on amplified uncertainty requires scope and options that allow differing solutions to work problems. However, if the organisation makes an increased range of options available and emphasises flexibility in handling work-related issues, this demands a greater degree of initiative and creativity from employees (Michel 2007). Learning organisations must trust their employees to deal with complex issues skilfully (Senge 1999). Viewed in these terms, obligatory adaptive learning approaches that reduce uncertainty and that promote the implementation of directives, standardisation and routines seem unlikely to offer the best approach for employees to participate in developmental learning.

\section{The Bank's intentions and business plan regarding learning}

Competition for bank customers has increased, and the Norwegian Competition Authority encourages customers to change banks regularly. The Banks business plan intends to offer all customers the best advisory service from the best and most competent employees. The Bank's senior management makes concrete and detailed demands on its local branches and employees regarding productivity and profitability. Strategic thinking is illustrated in a quote from strategic plan: "We succeed when we perform tasks correctly the first time". Task mastery is measured by the Balanced Scorecard which is a management system that ties 
strategic actions to the solution of work tasks (Kaplan \& Norton 1996). The Balanced Scorecard uses new technology to help senior management monitor and implement the organisational strategy at regional, departmental and individual levels. All employees have to record their sales and learning activities in the Balanced Scorecard. Web-based registrations are also based on the assumption that measurement of activity increases production (Nørreklit 2003). In their review article (Paranjape, Rossiter \& Pantano 2006) criticize this system as it promotes a strong top-down management by organizing the employees' work tasks in detail.

Learning activities is an indicator in the Balanced Scorecard and the stated strategy reveals two main intentions:

1) To create an opportunity for learning through sharing knowledge and experiences for the promotion of communication and cooperation within and between departments;

2) To provide a method for implementing new knowledge rapidly within the organisation.

All employees should contribute with their own initiatives for learning activities and this should not include teaching, lectures or receiving information. This "elbow room" for learning within the working day requires the participation of two or more employees. The requirement was originally for six half-hour meetings a month which later became more flexible three hours meetings. The requirements for receiving attendance bonuses changed in line with this and were abolished in 2009.

\section{Research method and sample}

The data used in "The Bank Study" include the strategy documents linked to the learning activities in the Bank. Two researchers attended, both singly and together, 35 learning activities at different levels and departments in the Bank in the same period. To enhance the empirical evidence eight, two-day focus groups were conducted in which three researchers and an average of ten office managers volunteered to discuss and analyse the bank's learning challenges. Two senior managers contributed in five of the focus groups. We interviewed singly 32 advisors and eight office managers, each interview lasting 30-60 minutes. Informants were randomly selected from five different branches of the bank with various age, 
gender and length of service. In these interviews an open-ended guide structured a constructive dialogue about the learning of both individuals and the Bank in general.

The data from the interviews, focus groups and ten learning activities were transcribed, in addition to written summaries from 25 learning activities. The material was categorised and analysed with the help of the computer programme NVivo 8 (Bazeley 2007). The qualitative material was first put into different categories based on factors and concepts revealed as important by informants. Thereafter these categories and work on patterns in the material were confirmed through discussions between researchers. This enabled comparison of the organisational strategy for, and the advisors and office managers' understanding of, learning activities in the workplace and how these agreed and differed (Dick 2007). When advisors and office managers talked about learning, they used the following categories: Information, credit routines, balanced scorecard, authorization, best customer process, sales and best prognosis.

The categorization of grounded data offered theoretical ideas for looking at patterns in the learning activities register in the Bank's Balanced Scorecard (Glaser \& Strauss 1967). Office management and employees in the Bank recorded in the Balanced Scorecard, themes and descriptions of all completed learning activities (2284) from 1.1.2008 to 30.06.2009. A weakness evident in this register of learning activities is the high number of short descriptions and there is also a possible lack of precision in the entries made. Self-reporting employees may copy each others' concepts while completing the required records, even if they had learned different content. The records also lacked a precise timetable, a fact that may be explained by changed requirements. Seven percent of the original material lacked descriptions and was taken out of the analysis. A possible bias may also be result from unrecorded learning activities.

To understand what kind of learning is emphasized at the Bank we categorized and summed up all the recorded learning activities based on the advisors and office managers own categories. Ellströms four-level theoretical model (2001) was used to analyse the register. This raised difficulties in categorizing, at adaptive or developmental learning levels, learning activities that both included information, discussions and reflection. Different content was often summed up in only one recorded learning activity and duplicated entries are sometimes evident. We therefore categorized $1 / 3$ of the learning activities in two or more categories to capture nuances. The inter-rater reliability was strengthened by the fact that the two 
researchers doing the analytical work, found consensus in the quantitative material and the recordings. Additionally the recordings were read carefully five times over a one year period.

\section{The learning activities in the Bank}

On the basis of the content description was all the 2284 learning recordings categorized and summarized. Our analysis is presented in the following table:

Table 2: Analysis of learning activities

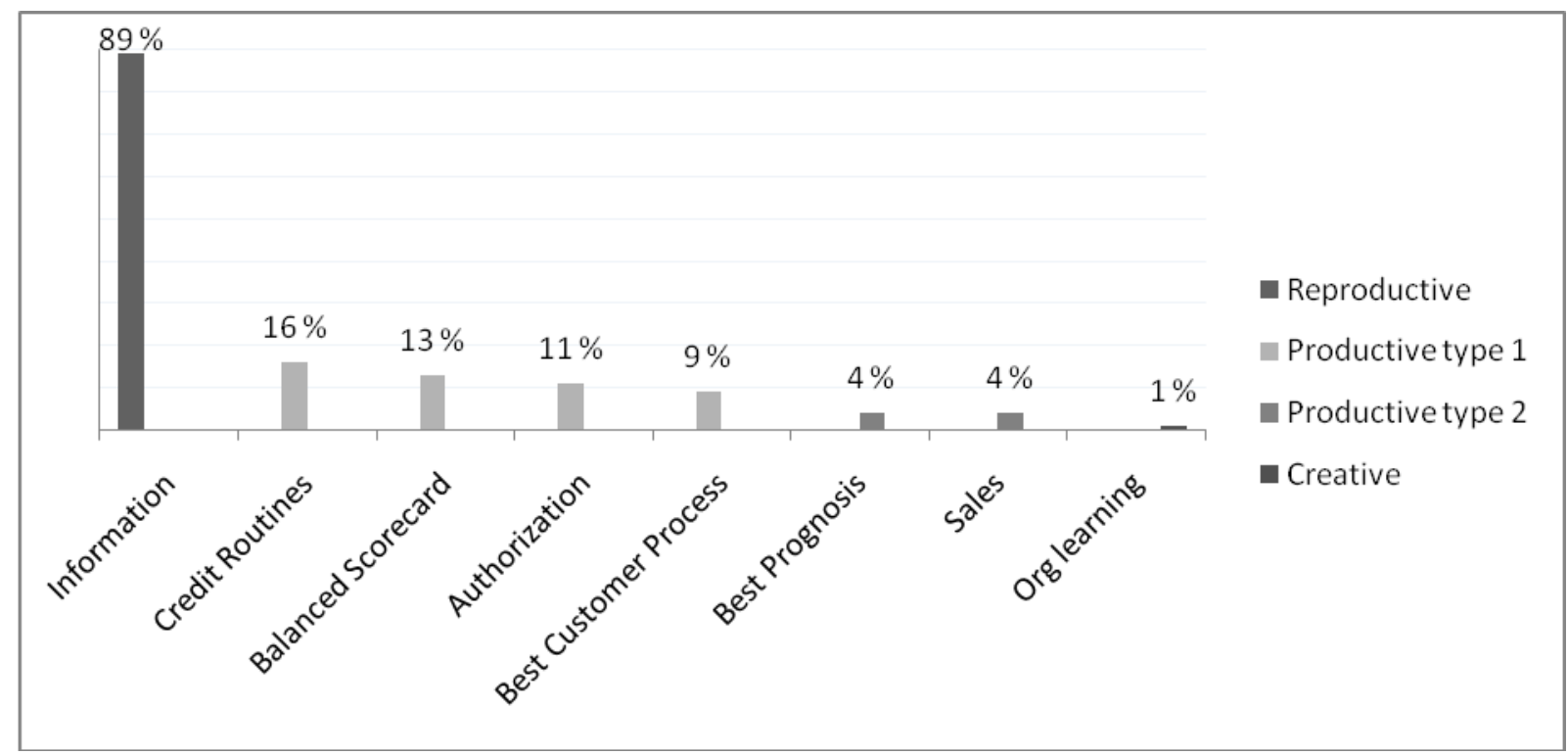

Table two reveals that the majority of all recorded learning activities contain information analysed as adaptive learning. Different information is presented at the same learning activity. To nuance these findings varied information is both characterized as reproductive (information) and productive type I (Credit Routines, Balanced Scorecard, Authorization and Best Customer Process). Developmental learning as productive type 2 learning (Best prognosis and Sales) and creative learning (Organizational learning) are limited recorded.

Information (89\%): Our analyses of the qualitative material and the recordings show that the registered learning activities are closely related to job descriptions and skills. New senior management directives and information about changes in sales, procedures, routines and measurements arrive by email to office managers and employees every month. Presentation of this information is the main content of the learning activities. The office managers the 
immediate superiors of the employees inform and lecture in most learning activities. In exceptional cases also employees have had this task of distributing information. The finance industry is strongly regulated by means of laws, credit rules and audits and a new authorization requirement for financial advisors. This requires quality-assured skills in order to prevent both breakdowns in trust and economic crime. Constant up-dating is necessary about new instructions, credit manuals and terms of reference. Product information about insurance, loans, savings and stocks is connected to the requirement for authorisation and to the Bank's strategy of attempting to sell several products to each customer. The volume of products has increased in the Bank, which creates a greater need for updating. At the same time, customers have increased their own knowledge about products and the macro-economy and therefore advisers feel a responsibility to be more up-to-date than their customers. In situations in which the customers know more than the employees a particularly uncomfortable uncertainty can be created at the customer meeting. Customers have a desire to meet advisers who know their specialist field thoroughly. Several advisors therefore also use product documentation as part of their preparations for meeting customers.

"You have to like learning in order to work in a bank" (informant in interview)

Updating their knowledge of products is time-consuming but can also be important and interesting. It is however impossible to know everything as one advisor mentioned:

"I am informed more than enough. I receive lots of additionally information from e-mail, internet and news as well (informant in interview).

Acquiring too much volume and detailed knowledge of products not relevant for their customers is viewed by employees as unnecessary. In such cases, the external demands and control are seen as disruptive.

Credit Routines (16\%): How employees prepare a customer proposal and handle cases is based on complicated credit regulations. Writing loan applications is seen as a challenge by employees because credit routines are increasingly changed and decision-making centralised. A quote emphasise this:

"New routines are constantly introduced you see" (informant in interview). 
Senior-management intends to reduce uncertainty amongst employees by means of tuition in credit routines. This intention is not carried out in all cases. Manuals and some parts of the information are so complicated and unmanageable that they increase uncertainty about how they are in fact to be used. In extreme cases this lack of control lead employees to take sick leave. We also have examples of descriptive reviews of the credit system that enable reflection in which the employees collectively go through the arguments and discuss difficult cases.

The Balanced Scorecard (13 \%): Our analysis reveals that sales statistics and various campaigns are used as a means of sharpening the focus of employees on sales. In practice, office management has responsibility for sections attaining their sales targets and for employees completing all the learning activities. The Balanced Scorecard sums up the results regularly as quoted below:

"Every time the results from the Balanced Scorecard arrive, all teams do a compulsory review" (Informant in interview).

By routinely going through the Balanced Scorecard, results and prognoses, both predictability and pressure is created. This kind of measuring increases management's control and decreases employees' participation and influence on work tasks. The use of Balanced Scorecards and too much continuous monitoring of personal results reduce cognitive uncertainty.

Authorization (11\%): The learning activities are also used for supporting employees in passing tests for an internal web-based certification system. The certification was replaced by new requirements for national authorisation for all financial advisors. The requirements for the authorisation are comprehensive and involve knowledge about products, routines and sales training. About twenty compulsory modules such as, macroeconomics, ethics, laws and regulations are required. Individual compendia have been compiled as preparatory material and many learning activities involve going through the compendia.

"Best Customer Process" (9\%): The senior management has approved a strategy of uniform customer treatment from all employees by the introduction of "best customer process". The goal is to sell several products to the same customer through better planning, running and 
follow-up of customer meetings in order to increase profitability. This process has been a challenge for several employees and the Balanced Scorecard has revealed considerable individual variation. By using internal resources, training is provided on implementing "best customer process". Roles are rotated with the office managers also taking part in the role play, in which one is an advisor, another is a customer and yet another is an observer. They have also been trained to initiate contacts with both new and established customers because of the high targets set for phoning and booking customer meetings. Training is regarded by employees as particularly useful when there is a need to rehearse specific skills. These rehearsals create a basis for learning by experience from each other. Training in itself contributes to adaptive learning and reproduction of routines and knowledge that attempts to reduce cognitive uncertainty about the best advice for all customers. Critical voices amongst office managers and employees ask how relevant and effective this training is when both the products and the customers are so varied.

"Best Prognosis" (4\%) and sales meeting (4\%): Learning activities also include discussions among all participants about the use of routines and work methods. The regular increase of requirements for unfamiliar prognosis and sales meetings give some potential for developmental learning and amplify cognitive uncertainty. Each individual employee and section sets his or her own targets in a "best prognosis" process which is regularly discussed and followed up in sales meetings. Such detailed measurement also gives office management a tool and an opportunity to give constructive feedback and see all the good work of the employees.

Organisational learning $(1 \%)$ happens when employees from departments or customer centres discuss ideas, present work models and collaborate to enhance the organisations sales. This organisational learning is categorized as creative learning because tasks, methods and results are not given and are influenced by participants. HQ divisions have recorded learning activities where changing routines or indicators in the Balanced Scorecard, improvement of credit manuals, products or information are the subject. When biases are detected HQ comes in with new fixed solutions for all employees and also changes indicators and bonus in the Balanced Scorecard to maximize profit. However, some of these learning activities may also be categorized as single loop adjustment of current practice (Argyris \& Schön 1996). This creative learning gives a potential for adaptive learning among all other employees. 
At a focus-group discussion, office managers described the learning activities as: "Instruction activities". They strongly emphasised certification and development of a formalised and factually-based learning approach from the learning strategy within the Bank. Office managers also reflected on the extent to which employees were systematically more attracted to information and lectures than to participating in discussions among colleagues. The lack of participation and responsibility for individual learning amongst employees was a source of frustration to the office managers. Given the two intentions about the learning activities in the senior management strategy document, this type of frustration is not surprising. The office managers also saw the dichotomy between intention and reality within the Bank as a clear challenge:

"The strategy of developing the Bank as a learning organisation encounters a culture of learning in which 'we are used to being trained" (informant in focus group).

This can also be explained by a learning culture that limits participants' involvement and influence within the organisation. The Bank and the employees do not regard the strong focus on adaptive learning as particularly unusual. However, employees emphasise that learning activities involving discussions about work manuals and products are felt to be positive and relevant. It is also easier to reflect over products and experiences when there are few participants. Flexible small groups with a large learning potential are used for ad hoc updating and discussing current customer questions at short notice. Learning activities are a challenge when work is hectic. It is difficult to catch up if one gets behind in taking part in them. The demands of learning activities also limit the employee's opportunity to use "slack" time for reading necessary technical literature:

"We have to read it, but there is no time for reading at work" (Informant in interview).

As such the employees also have to use their spare time to keep themselves professionally updated.

\section{Strengthened adaptive learning and reduced cognitive uncertainty}

The volume of knowledge and authorization requirements within the organisation are increasing, which makes setting aside time for learning a good strategy. It is reasonable to 
regard learning activities as a reinforcement of adaptive learning because, in practice, the employees are measured on the use of routines and instructions carried out. Senior management in the Bank has emphasised that it was a clear intention of the new strategy in practice to focus on adaptive learning on routines for different types of work operations. This intention is followed up by both office managers and advisors. The problem with the strategy is that absorbing the volume of fact-based knowledge that is required by advisors in the Bank precludes time for reflection. When learning activities are filled up by excessive adaptive learning for dealing with peripheral themes and problems, advisors drown in information. The flood of descriptions and adaptive learning explains why the sharing of knowledge and experience which was the stated intention of the learning activities is rarely recorded. This reduces developmental learning because the participants do not critically review their actions and experiences with each other. Reflection might better ensure the quality of learning about, for instance, the authorisation system and "best customer practice". A large number of learning activities erodes time for important sales/follow-up work. It can contribute to a conflict between operational work and learning.

Our material reveals that bankers' ability to reflect is under pressure because of lack of time, regulations and laws that are not open to discussion, and demands for knowledge and efficiency. This evident lack of reflection goes against what is advocated by much theoretical work on learning at the workplace (Ellström 2001) and cognitive uncertainty (Michel 2007). Because the Balanced Scorecard is a strategic tool for strong senior management and control, adaptive learning becomes the strategic tool for implementing centrally-agreed resolutions. The theme of developmental learning as a potential growth factor has received very little attention in our Bank. Hierarchical top-down organisations favour increased standardisation and reduced cognitive uncertainty but this approach hinders the growth of new ideas and working methods amongst the employees and are also supported by Voelpel, Leibold, \& Eckhoff (2006). Finance organisations needs creativity among its employees to improve products, sales and processes. A formalised learning unit providing individual adaptive learning can, in practice, hinder developmental learning and can erase constructive criticism both within departments and organisation. Too much adaptive learning also reduces time for collaborative learning and experience-sharing about the solution of work tasks in organisations. The world of international finance is changing radically and this amplifies cognitive uncertainty in dealing with the existing and future wealth of individuals and companies. As such our empirical and theoretical contribution indicates a need for a balance 
between the demands for adaptive learning about regulations and quality standards and the need for developmental learning about service and sales. International and national policy regulations and quality standards lend legitimacy to, and might explain the systematic use of adaptive learning to reduce cognitive uncertainty. The strategic use of routines and adaptive learning contributes to an important quality assurance that all employees solve the work tasks with the same methods. In addition developmental learning that amplifies cognitive uncertainty also contributes to important critical thinking among employees that validates the use of work tasks, methods and results.

\section{Conclusion}

Our research show that time regularly set aside for necessary information updates and workplace learning is important in a hectic work situation with a strong focus on sales. Within the organisation we have studied, learning is strongly focused on factual knowledge, routines and rehearsal. The Bank emphasises adaptive learning to increase sales and reinforces the use of routines and knowledge in a business in which customer trust and government regulation are central in the sale of financial products.

We argue that specifying a number of obligatory learning activities does not necessarily contribute to organisational improvement. The Bank's strategy states the intention of sharing experience and learning among employees. The result has been a considerable emphasis on adaptive learning that emphasises pedagogic attitudes of security and trust. Descriptive surveys of products and practice of routines preclude time for discussion and reflection. The Bank's strategy of developmental learning does not correspond with praxis. New authorization demands and strong traditions of training which reduce cognitive uncertainty become barriers to employees influence and participation. Organisational recipes such as the Balanced Scorecard are couched in the rhetoric of increased developmental learning. In practice, however, they can easily become a senior-management tool for increased adaptive learning. This reduces employee's cognitive uncertainty in solving work tasks and restricts employees' opportunity to question, influence and participate in reflection and developmental learning. As such, the adaptive learning prohibits alternative and new possibilities both on individual, departmental and on the organizational level. The Bank's intention of providing "elbow room" for learning can, in practice, be further developed in order to increase 
developmental learning and an organisational culture with room for critical reflection on current practice.

Although this qualitative study is based on multiple and triangulated observations the methodology is limited in that it raises the question of how far one can accept the validity of generalisations arising from one case only. It is also a possibility that developmental learning may happen more often in reality than implied by the register because such initiatives are difficult to describe with few words. There is therefore a risk that the role of adaptive learning characteristics has been overstated in the analysis and that developmental learning is not sufficiently perceived in the overall picture. Developmental learning may occur, for instance, when customer issues are critically discussed informally with colleagues and this would not be accounted for by the research methods we chose.

More research is needed about how organisational strategies promote learning and cognitive uncertainty connected to employee's solution of work tasks. The distinction between the terms adaptive learning and developmental learning contributes to a better understanding for organisational researchers, management and employees who wish to discuss how it is possible to increase learning in organisations. Connecting adaptive and developmental learning to the theory of cognitive uncertainty helps to develop our understanding of learning activities and strategies in organisations. Clarifying the nature of the diversity of these different approaches to learning provides a better basis for forming a nuanced strategy for individual and organisational learning. The challenge will be to find the optimal point of balance between adaptive and developmental learning and between reduced and amplified cognitive uncertainty.

\section{References}

Argyris, C \& Schön, DA 1996, Organizational learning II theory, method, and practice, Addison-Wesley series on organizational development, Addison-Wesley, Reading, Mass.

Barnett, R 1999, 'Learning to work and working to learn', in D Boud \& J Garrick (eds), Understanding learning at work, Routledge, New York.

Bazeley, P 2007, Qualitative Data Analysis with NVivo, Second Edition edn, Sage publications Ltd, London. 
Beck, U 1997, Risk society: towards a new modernity, Sage Publications., London.

Bottrup, P \& Clematide, B 2005, 'Workplace learning from the perspective of institutionalized learning', paper presented to International Conference on Researching Work and Learning: 4th, , Sydney, December, <http://www.projects.education.uts.edu.au/RWL4/RWL4Papers/6746.doc>.

Boud, D, Cressey, P \& Docherty, P 2006, Productive reflection at work - Learning for changing organizations, Routledge, London.

Dewey, J 1991, How we think, Promethus Books, N.Y.

Dick, B 2007, 'Grounded theorists and action researchers', in A Bryant \& K Charmaz (eds), The Sage Handbook og Grounded Theory, Sage Publications, London, pp. 398 - 416.

Dreyfus, H \& Dreyfus, S, E 1986, Mind over Machine - The power og human intuision and expertice in the era of the computer, The Free Press, New York.

Ellström, P-E 2001, 'Integrating learning and work: conceptual issues ans critical conditions', Human Resource Development Quarterly, vol. 12, no. 4.

Emerson, RM 1962, 'Power-Dependence Relations', American Sociological Review, vol. 27, no. 1 , p. 10.

Fenwick, T 2008, 'Understanding Relations of Individual Collective Learning in Work: A Review of Research ', Management Learning, vol. 2008, no. 39, pp. 227- 43.

Giddens, A 1990, The consequences of modernity, Polity Press, Cambridge.

Glaser, B \& Strauss, AL 1967, The discovery of grounded theory: Strategies for qualitative research, Aldine, Chicago.

Goldman, E, Plack, M, Roche, C, Smith, J \& Catherine, T 2009, 'Learning in a chaotic environment', Journal of workplace learning, vol. 21, no. 7.

Illeris, K 2004, 'A model for learning in working life', The Journal of Workplace Learning, vol. 16 , no. 8 , pp. 431-41.

Jørgensen, CH \& Warring, N 2002, 'Læring på arbejdspladsen', in K Illeris (ed.), Udspil om laring $i$ arbejdslivet, Learning Lab Denmark, Roskilde Universitetsforlag, Fredriksberg, p. $219 \mathrm{~s}$.

Kaplan, RS \& Norton, DP 1996, The balanced scorecard translating strategy into action, Harvard Business School Press, Boston, Mass.

Krugman, P 2009, 'How could the economist take it so wrong', New York Times, 2. October.

Levinthal, DA \& March, JG 1993, 'The Myopia of Learning', Strategic Management Journal, vol. 14 no. Organizations, Decision Making and Strategy, pp. 95 - 112. 
March, JG 1991, 'Exploration and exploitation in organizational learning', Organization Science, vol. 2, no. 1, pp. 71-87.

Marton, F \& Säljö, R 1976, 'On qualitative differences in learning: I. Outcome and process.', British Journal of Educational Psychology, vol. 46: , no. 1, pp. 4-11.

Michel, A 2007, 'A Distributed Cognition Perspective on Newcomers`Change Processes: The Management of Cognitive Uncertainty in Two Investments Banks', Administrative Science quarterly, vol. 52, pp. 507-57.

Michel, A \& Wortham, S 2009, Bullish on Uncertainty. How organizational cultures transform participants, Cambridge university press, New York.

Nørreklit, H 2003, 'The BSC: What is the score? A rhetorical analysis of the BSC', Acounting, Organizations and Society, vol. 28, pp. 591-619.

O'Reilly, CA \& Chatman, JA 1996, 'Culture as social control: Corporations, Cults and Commitment', in B Staw \& L Cummings (eds), Research in Organizational behavior, JAI Press Inc, vol. 18, pp. 157-200.

Paranjape, B, Rossiter, M \& Pantano, V 2006, 'Performance measurement systems: Successes, failures and future - a review', Measureing Business Excellence, vol. 10, no. 3, pp. 4-14.

Schøn, D 1987, Educating the Reflective Practioner, Jossy-Bass Publishers.

Scott, WR 1992, Organizations. Rational, Natural, and Open Systems, Third edn, Prentice Hall, New Jersey.

Senge, PM 1999, The Dance of change: The challenges of sustaining momentum in learning organizations, Currency/Doubleday, New York.

Trope, Y \& Liberman, A 1996, ' Social hypothesis testing: Cognitive and motivational mechanisms.', in ET Higgins \& AW Kruglanski (eds), Social Psychology: Handbook of Basic Principles, Guilford Press., New York: , pp. 239-70.

Voelpel, SC, Leibold, M \& Eckhoff, RA 2006, 'The tyranny of the BSC in the innovation economy', Journal of Intellectual Capital, vol. 7 no. 1, pp. 43-60.

Wenger, E 2000, 'Communities of Practice and Social Learning Systems', Organization articles, vol. 7, no. 2, pp. 225- 46. 